\title{
Commentary
}

\section{Small Market, \\ Big Format: Idols in Estonia}

\section{DE DE GRUYTER}

OPEN

ULRIKE ROHN, University of Tartu; email: ulrike@rohn.as 


\section{ABSTRACT}

This article looks at the factors that have influenced the Estonian adaptation of the Idols format, Eesti otsib superstaari. Based on existing literature, as well as on interviews with representatives of the local TV industry, this article suggests that the most influential factor is the small size of the Estonian TV market. Most changes to the original format have been made for practical reasons and not due to cultural considerations. Hence, this article argues that it is mostly market and industry logistics that influence programme imports and local adaptations and not so much the cultural shareability of such programmes.

\section{INTRODUCTION}

\begin{abstract}
Shows usually don't travel. It is very difficult to produce a format that travels internationally. And when adapting it to a market a lot of parties and forces are involved. The final product is usually a result of something very complex. (Personal interview with an Estonian TV producer.)
\end{abstract}

TV formats are adapted for local audiences around the world, and while we are fascinated with the success of such formats that are internationally successful, we often do not understand why a particular format is adapted in a particular way for local audiences. In this context, this article aims to understand the translation process of the music competition format /dols in Estonia.

\section{THEORETICAL FRAMEWORK}

A lot of research focuses on the success of the global TV format trade, and there are many examples in the literature that describe the interplay between global or local elements within particular format adaptations (Aslama, Pantti 2007; Beeden, de Bruin 2010; Turner 2005). Some research also aims at understanding why some content or content elements are adapted for local audiences whilst others are not. In this context, the approach of cultural translators by Kyle Conway (2011) emphasises the in-between position of media producers between the origin of the content and the target market of the content, and argues that the forces that affect local network executives and media producers in their decision-making processes shape the programming produced as text.

Much of the previous writing on the international trade in TV formats looks at the nature of the content and its cultural shareability (Singhal, Udornpim 1997) with the local audience and how that may influence decision-making regarding the import of foreign content and its adaptation for local audiences, or at the reasons that lie in the logic of the industry and its markets. This article will look at both.

With regard to reasons that lie in the nature of the content, local producers, and network executives who aim at offering programmes that are most successful with their audiences will aim to offer content that is culturally most proximate to their audience thereby avoiding the offer of a cultural discount (Hoskin, Mirus 1988). According to the concept of cultural proximity, first introduced by Joseph Straubhaar in 1991, audiences prefer content that appears close to their own culture. Elements that 
make media content culturally proximate include native language, or culture specific things such as humour, gender images, dress style, life style, ethnic types, religion, and values (Iwabuchi 2002; Straubhaar 1991). If an international format offers the "crust" of a programme (Moran 2004: 264), then the "filling" of the format with content through local production is what may make content more culturally proximate.

I have elsewhere (Rohn 2010a, 2011) introduced a so-called Lacuna and Universal Model that helps to understand why programmes or programming elements may or may not be successful when introduced to audiences outside the culture of production. In this model, the term "Lacuna" stands for the phenomenon when the cultural differences between the culture of the origin of media content and the culture of the target audience negatively influences the success of the content with the audience. "Universals", on the other hand, are attributes of the media content as well as of the relationship between the content and the audiences that help to overcome cultural differences between the culture of the origin of the content and the culture of the target audience. Where Universals exist, audiences select and enjoy foreign TV formats and programming elements despite their origin from a different cultural environment. Whereas the Lacunae only regard reasons for local adaptation that lie in the nature of the content, Universals also consider reasons that lie in the logics of the industry or market.

In detail, the model distinguishes three types of Lacunae as cultural barriers to the cross-cultural success of TV formats and programming elements as influencing factors for decisions by local producers and network executives to buy foreign programmes and formats as well as on their decisions on if and how to adapt them for local audiences. They are: Content Lacunae, Capital Lacunae, and Production Lacunae.

Content Lacunae occur where audiences find TV programmes that originate from outside of their culture inappropriate or irrelevant. A TV format that has per- sonal expressions and affections at its core might not be successful in countries where such things are regarded as private matters and should not be brought up in public. To make a foreign TV format more relevant and appropriate to local audiences, a local production includes a local cast who behave in a way that is acceptable in the particular culture. Local celebrities who act as hosts or jury members will also help to attract local audiences with their existing fame, thereby making the programme more relevant.

Capital Lacunae describe the phenomenon where local audiences lack the necessary knowledge to understand the foreign formats and programming elements in order to enjoy them. The most obvious Capital Lacunae occur when the content is in a language foreign to the audiences. Hence, local productions are in the local language and in most cases the name of the TV format is translated. Foreign productions may also make obvious Capital Lacunae when audiences are unfamiliar with people, places, events, and so forth, to which they refer to. In particular, TV formats that are quiz shows require a lot of culturally specific knowledge and questions very often need to be developed uniquely for the local market and cannot be taken from the original format.

Production Lacunae refer to the phenomenon when audiences do not enjoy foreign TV formats or programming elements because they do not like the style in which they were produced. Some audiences, for instance, may be used to more complex and complicated storylines, and dislike simple ones. Though licensing agreements between a format holder and the local producer may include strict rules regarding some of the aesthetic standards, such as the studio design, the source, and use of lights, the use of colour and music, local producers may make the style of a singing competition, for instance, more proximate to the local culture by having the contestants perform local songs.

In contrast to Lacunae, which call for local adaptation, Universals make foreign 
TV formats or programming elements culturally shareable, a term coined by Arvind Singhal and Kant Udornpim (1997). The Lacuna and Universal Model distinguishes three types of Universals, two of which are reasons for cross-cultural success that lie in the nature of the content: Content Universals and Audience-Created Universals.

Content Universals are content attributes that are enjoyed across different cultures. Thus, a theme or topic of a TV format may arouse emotions that appeal across cultures. The heart-touching story of a person's dream come true, for instance, or competition between contestants, stories of love and romance, or programming elements that allow for escapism into a fantasy world may be enjoyed by audiences from different cultures. Very often, TV formats are also enjoyed when they represent something new and refreshing compared with the usual media supply in the country. Due to the production experience and know-how that many international format holders share with the local producers, local productions of international formats are often of high production quality and stand out from other productions offered in the market.

Audience-Created Universals refer to the phenomenon where audiences enjoy TV formats and programming elements from a different origin because of the particular way in which they read them. This may be the case where the text is "open" (Eco 1998) or provides for "semiotic democracy" (Fiske 1987), whereby it delegates meaning-making to the audience. Scott R. Olson (1999) speaks of a "transparent text", which includes narratological devices such as open-endedness or leaving out the details, that allow readers to project their own narratives, values and meanings onto the text.

The third type of Universals, which is part of the Lacuna and Universal Model (Rohn 2010a, 2011), are the Company-Created Universals. In contrast to the Lacunae and Universals described above, Company-Created Universals represent influences on the decision whether to import or whether to and to what extent to adapt the production for the local audiences that have their nature in industry and market logics and not in the nature of the content. Due to Company-Created Universals a foreign TV format is successful in a market or needs little or no adaptation when companies have managed to create a competitive advantage for it relative to other media in the market. Thus, format sellers or local network executives may strategically position formats through marketing strategies, which include tools that concern promotion.

The Lacuna and Universal Model that, with the exception of Company-Created Universals, focuses on cultural influences on the translation process is part of the Vertical Barrier Chain that I have introduced elsewhere (Rohn 2010a, 2010b). The Vertical Barrier Chain serves as an analytical framework that organises all internal and external forces that may influence international media trade decisions in terms of a standardised approach or an approach of local adaptation. In the Vertical Barrier Chain, forces in the regulatory, political, economic, and cultural environment are labelled "barriers" to the extent to which they may represent filters to the successful entry of foreign media concepts and programming elements. Furthermore, they may present reasons why a local adaptation of a format and its elements may not be possible or allowed.

With regard to regulatory or legal barriers, a local TV station may not be allowed to buy a particular TV format or adopt certain programming elements if the concept of the programme or these elements violate content standards set by the law in the market. Furthermore, the legally binding licensing contract between the format holder and the local company may constrain the type of programme being offered. The licensor is usually interested in keeping the local production of its format recognisable as a distinguished format, since it wants to remain a recognisable format that heightens the value of the format as a global brand. Hence, key branding elements, which may include the logo, the set design, musical content, episode segments, or programming 
rundowns must not alter across territories and cannot be subject to local adaptation. As part of the licensing agreement, local producers usually receive clear guideline on how the programme should look in the form of the so-called workshop notes, previously known as production bibles.

Political barriers to a successful market entry are most crucial for ownership entry because the political environment in a market may negatively impact a company's investment return (Root 1994: 152). They are less relevant for content entry and entry through licensing deals. Yet, some extreme scenarios, such as a war, also make licensing deals unlikely. Similarly, low-efficiency and corruption related to administrative and bureaucratic procedures may affect decision-making in the TV format trade. Furthermore, the lack of intellectual property rights protections in some countries may also represent a political barrier to successful entry by foreign TV formats. While some elements of a TV format, such as the logo or the music content, may enjoy copyright or other legal protection, TV formats are not generally protected under copyright law (Kretschmer, Singh 2010). Where the practice of format copying is common, foreign TV formats are usually already produced locally without official licensing deals. As a result, there may be no demand for legal, but expensive, licensing deals to produce TV formats. Format copying has, in fact, become a by-product of the growing international trade in format rights and it is not uncommon even for highly respected companies (Kretschmer, Singh 2010).

In terms of economic barriers, the Vertical Barrier chain distinguishes between economic forces within the target market and within the companies engaged in possible licensing deals. Colin Hoskins et al. (1994) emphasised that the economic environment plays a large role in how the cultural industry works.

With regard to the economic environment in the market, the size of the market may influence a company's decision whether to buy foreign TV formats and whether to and to what extent to adapt them for local audiences. In fact, previous research has identified market size as a key determinant for any explanation of how the TV industry works (Lowe et al. 2011; Puppis et al. 2009; Siegert 2006; Trappel 2011). The larger a market, the more it justifies a costly strategy of localisation because of the increased revenue and profit opportunities. Small markets, on the other hand, are too small to realise economies of scale (Puppis et al. 2009) because in small markets the high fixed costs for producing a programme cannot be distributed among a large number of audiences. As a result, the average production costs to serve one viewer remains high. Hence, companies in small markets are likely to also keep their production costs low and not to invest large resources into localising content. Another reason for not adapting for local audiences in small markets may be the fact that there are fewer personal and financial resources available. Also, the competitive structure in the market may influence decision-making by local production companies and TV stations. Where competition is high, companies are likely to invest in adapting a format to make it most culturally proximate to the local audience and avoid offering a cultural discount (Hoskins, Mirus 1988).

In terms of economic forces within the companies engaged in importing international TV formats, the strategic positioning of the local TV station is most likely to influence whether it buys a license and to what extent it adapts it to local audiences. The strategic positioning is often influenced by the primary source of revenues as well as the demographics of the audience. Also the economic situation and the available resources of the TV production company as well as that of the TV station may influence the decision-making process. Furthermore, the reputation and negotiation powers of both the local production company and the format owner are likely to influence the licensing deals. And local production companies that regard the production of TV formats as their core competencies are more likely to buy and adapt international formats compared to companies that are not 
as experienced in the production of TV formats. The latter will most likely rely on the assistance of the so-called flying producers that are sent by the format holders. Not only do flying producers bring to the production the knowledge gained in producing all the previous productions, they also keep an eye on the local production in terms of keeping the original format's values and key elements the same across territories (Kretschmer, Singh 2010).

Cultural differences or cultural similarities between the culture of origin of the format and the culture of the target audiences that are obvious in the nature of the content may influence decision-making in the international TV format trade through the abovementioned Lacunae and Universals. Yet, there may also be cultural reasons that do not lie in the nature of the content. As cultural values also influence business behaviour and business relations, both among co-workers within a company and between employees of different interacting companies (Hofstede 2001), these also may influence how the TV industries in different countries operate, the nature of the licensing deals and how local productions are put into practice.

In sum, the forces that may influence the decision-making in the international trade of TV and that shape the text of a format adaptation are wide-ranging and include cultural, legal, political, and economic forces. In the following section, this article will look at the Estonian version of the Idols format, Eesti otsib superstaari.

Based on interviews with representatives of the TV industry, the following section takes a closer look at what has influenced the import as well as the translation process of this format in Estonia.

\section{CASE STUDY: THE ESTONIAN VERSION OF IDOLS}

\section{Background: The Estonian TV market}

Estonia with 1.34 million inhabitants makes for a very small TV market of 0.5 million TV households (Mavise 2012). What is more, Estonia, which was part of the Soviet-Union until it regained independence in 1990-
1991, has a large Russian-speaking minority, which accounts for $26.3 \%$ of the total population (Eesti Statistikaamet 2011). The majority of Russian-Estonians feel very connected to the Russian culture, which is mirrored in the fact that they predominantly watch Russian TV channels (Vihalemm 2006; Vihalemm et al. 2012). While Russianlanguage TV channels are popular among the Russian minority, none of these are based in Estonia (Örnebring 2011). Hence, this orientation of the Russian-speaking minority towards TV channels from Russia effectively makes the market for Estonian TV stations even smaller.

The Estonian TV sector has undergone fundamental changes since the restoration of the country's independence. During the Soviet era, TV was Soviet-controlled and had the ideological mission to distribute Soviet propaganda (Open Society Institute 2005: 33). After the end of the monopoly of Soviet-controlled state TV, the public service broadcasting system ERR was established, and commercial broadcasters started to blossom (Open Society Institute 2005: 554-556). Today, Estonia's TV market is free and competitive (Örnebring 2011) with three TV stations dominating the market: the public station ETV, which had a market share of 17.3\% in December 2013; the commercial TV station Kanal 2, which had a market share of $14.2 \%$ for the same month; and TV3 with a market share of 11.5\% (TNS Emor 2014).

The processes of liberalisation and the introduction of the commercial broadcasting sector enabled the internationalisation of ownership of the Estonian TV sector. In fact, a large part of the Estonian TV sector has been controlled by foreign, mainly Northern European capital. Thus, Kanal 2 is owned by the Swedish media conglomerate Modern Times Group and the owning company of TV 3, Eesti Meedia, was owned by the Norwegian company Schibstedt until it was fully bought up by Estonian capital in 2013. The internationalisation of the TV environment in Estonia has also led to an increasing internationalisation of programming (Stetka 2012: 109). 


\section{Foreign TV content in Estonia}

Even before the restoration of independence, Estonians could watch foreign TV content. Not only was Russian content always available during the Soviet era, Finnish TV broadcasts could be watched by much of the Estonian population due to the geographic closeness between the two countries (Open Society Institute 2005). Since the two languages are very similar the content was quite accessible to Estonians. As Finland was outside of the Soviet-Union, "Finnish TV was not just a window to Finland, it was a window to the world for Estonians," one of the interviewees said. Furthermore, Finnish TV programming was seen to be more entertaining and of higher production quality than what was offered in Estonia, according to the interviewee. The influence that Finnish TV had during the Soviet era, not only on audiences but also on Estonian TV producers and directors, however, vanished quickly after the regaining of independence and with the opening of the Estonian market to international channels (Vihalemm et al. 2012). Furthermore, the Estonian public channel ETV started to import foreign programming, and the new Estonian commercial channels offered international content as soon as they were launched.

According to one of the interviewees, three reasons were behind the large increase of foreign content offered after the regaining of independence. The first two reasons were the relatively cheap price for foreign programmes and the limited resources available in Estonia as a small market:

Acquisitions are always cheaper than own productions. The greatest programmes are ten, twelve or 15 times cheaper than own productions. But it is not only about the price. It is also about the ability to produce the quality of content that people would want to watch. And this is sometimes difficult in small markets.
The third reason for the success of foreign TV imports were cultural, according to him:
International content is suc- cessful in Estonia because of some sort of open-mindedness towards the rest of the world that is very common here. Maybe it is because Estonia has a long past with foreigners. For the last 700 years, Estonia has been occu- pied so much, it always needed approval from others. We were always dependent on others and needed to know what the others think of us.

Even today, the interviewee said, international content was more successful in Estonia than it was in the other two Baltic and former Soviet-Union countries Latvia and Lithuania. Foreign programmes are usually not dubbed in Estonia, due to the high costs for dubbing that are not reasonable in the light of the small size of the market. But instead of voice-overs, most foreign programmes are shown with subtitles in Estonia. As the interviewee explained, "Estonia is the only country in the Baltics where people want to hear the original."

While there is quite a lot of import of ready-produced scripted drama in Estonia, hardly any foreign format of a scripted series has been produced in Estonia. An interviewee explained this with reference to the small size of the Estonian market and its limited financial resources:
Usually, adapting drama formats means that the original script writers rewrite or remake the script for your audience. Then these scripts get translated and local scriptwriters might add things or change things, this again needs to get translated. This means that many people are involved in the process sending scripts back and forth around the world. This makes it very expen- 
sive. Estonia cannot afford it. The market is too small.

The scripted TV format Ugly Betty was not produced as an adapted version in Estonia for yet another reason. Thus, the US version of the series that was sold to Estonian broadcasters was very successful with Estonian audiences. Instead of stimulating the demand, which such tape sales are usually intended to, the tape sale resulted in the opposite, as network executives did not see a demand for an Estonian adaptation after the success of the original version. As a former programme director said, "You cannot tell the same story twice, especially when the market is not fragmented. And it is not fragmented here in Estonia. It is too small for this."

In contrast to scripted TV formats, local adaptations of foreign unscripted TV formats are very common in Estonia. The first Estonian adaptation of a foreign format was that of the US format The Dating Game, which premiered on the public channel ETV in 1993. Being the first entertainment programme in Estonia that featured ordinary people with non-scripted narratives, it presented something very new to the local audience. The show was very successful and was broadcast for ten years (Laasi 2010: 7).

Also very successful was a pan-Baltic version of the reality TV game show Survivor, which was co-produced with a Latvian and a Lithuanian producer and which included an Estonian, Latvian, and Lithuanian cast. A former programme executive of TV3 that aired the show, which was named Robinsonid in Estonia, from 2000 to 2004 explained the success of the show as follows:

Because it was a pan-Baltic edition, we had the money from three countries. It was ten times more expensive than our most expensive programmes in Estonia so far at this time. The production quality was so high, no one ever had seen anything like that before.
It changed television in Estonia. After Robinsonid, every other locally produced programme looked cheap compared to this. It was successful, even though we had to subtitle most of the programme because the contestants were also from Latvia and Lithuania.

Also very successful was the Estonian adaptation of the globally popular quiz show Who Wants to be a Millionaire, which was produced and broadcast for six years. Though it was very successful, it did not come as a surprise to one of the interviewees that the show ceased in 2008:
A show only works if you amaze your audience. And you can only amaze them for so long. It's a fashion, a mood. And this stops at some point. Also, the show was very expensive to produce. The prize fund is actually very big. What is also expensive is the set, as you have to keep it for years, and you cannot use this space for anything else but for this show. So when you are not recording, it is a waste of space and money. It is OK to have all these costs when your programme is in the top five or so, but if it is not, it is too expensive. And you cannot be in the top five for so many years. You have to bring in something new, you cannot amaze your audience with the same show for six years.

In 2007, a new wave of very successful international formats started with the launch of the Estonian adaptation of Dancing with the Stars, which was broadcast until 2007. One of the interviewees described the success of the format in Estonia as follows:

The money that one had to put into the production was established by the BBC. So they said that we must not produce it any 
cheaper. The idea of the show is very simple, so it is very important that you produce it very well. It has to be glamorous, you have to put in a lot of resources to make it successful. And we did. But this is something we usually cannot do in such a small market as Estonia is. Or at least, we cannot produce too many such formats; we just don't have the money for it.

Around the same time as Dancing with the Stars was launched in Estonia, an Estonian version of The Apprentice was introduced. This show, however, failed to attract large numbers of audiences (Laasi 2010: 41). The key factor for the success of the original version is its host, Donald Trump, whose personality is part of the format. According to the format, local adaptations have to include hosts that are similar to him in style and character (Huff 2006: 13). The Estonian host, however, could not match Trump's charisma (Laasi 2010: 41), and he appeared artificial and dull. One interviewee commented on this: "Finding the right cast is difficult in small markets. There are not so many people to choose from."

The majority of the foreign formats produced in Estonia come from the

US, Sweden, the Netherlands, and the UK (Laasi 2010: 7). The Estonian TV market has more content and influences from other European countries than from Russia, and Estonians identify themselves more with the West and other European countries than with Russia (Aalto 2003). Most of the programmes of foreign origin are broadcast on the commercial channels, while over $70 \%$ of the programmes on the public channels are of Estonian origin (Eesti Rahvusringhääling 2009: 18). Furthermore, studies have shown that it is mostly the younger audiences that watch programmes of foreign origin (Kalmus et al. 2013).

\section{Idols in Estonia}

Idols is one of the most successful TV formats worldwide. It originates from the UK, and it is co-owned by UK-based Fremantle
Media and US-based 19 Entertainment and has been produced in 46 territories (Fremantle Media 2014). Idols is a knock-out music talent show, and all of the local productions have the same goal: to address the entire nation or territory in a quest for one "idol" (DeBruin 2012: 225). A strong element of the show is the jury, which usually consists of five members who comment and offer advice after each contestant's performance.

In the quest to become an idol, contestants go through different stages: 1) Auditions are held in various cities and people are given the chance to sing in front of music and TV producers and, if successful, in front of the show's jury in recorded televised auditions. According to Huff (2006), this is the stage where viewers are drawn by the I-can't believe-what-l'm seeing factor when a really bad singer performs. 2) Theatre rounds in which a selected group chosen from the auditions converges and engages in workshops as well as starting to perform on stage. The theatre rounds consist of three sub-stages in which the contestants sing both in groups and individually and after each of these stages a number of contestants are eliminated and sent home by the jury members. 3) Semi-finals of individual performances in a TV studio. Also in this stage, judges comment on each contestant's performance but starting from this stage until the end of a season, audiences can vote for their favourite contestant(s) via text messages or calls and thereby eliminate those they dislike. 4) The live shows are elaborate and spectacular versions of the semi finals, and they include weekly themes which contestants must base their songs on. The live shows continue until there are only two or three contestants left, which will then lead to 5) the Grand Final. What makes the format special is that it showcases the contestants' life stories and follows them from the first auditions to the final (Kretschmer, Singh 2010).

The local production of the Idols format, Eesti otsib superstaari, was launched in Estonia in 2007, and it instantly became one of the most popular TV programmes 
in the country. While most popular programmes in Estonia generally have fewer than 300,000 viewers, the finale of the show in December 2009 had 303,000 viewers (TNS Emor 2009), making it the most successful programme during the time. As the Russian Estonian viewers mostly watch the Russian version of the format, which they receive via Russian broadcasters, the target group for Eesti otsib superstaari were mainly the ethnic Estonian viewers.

The show was produced in five seasons between 2007 and 2012, and it was broadcast on the commercial channel TV3. The local production company was Ruut. According to one of the interviewees, a flying producer from FremantleMedia came to Estonia during the production of the first four seasons and consulted on the process.

Though the ratings were still fairly high in 2012, Eesti otsib superstaari was not continued after that year. One of the reasons for this was, according to one interviewee, that the production company started to produce the local adaptation of Your Face Sounds Familiar, a format that also involves celebrity judges. As an interviewee reported:

They (the production company) are doing a new show. You cannot have many large shows in this country at the same time. In order to survive in Estonia, you need to have ten to $15 \%$ of the audiences; otherwise, the number of your audience is too small to get your money back. In countries like the US, $2 \%$ of the audiences are enough. So there is not much space for successful shows in Estonia. Also, the production company would be messing with the jury from one show to another. There are not so many people here you can use for your jury. When you want to offer something new, then you might have to stop an existing show, and this is what happened.

\section{Reasons for the success of Eesti otsib superstaari}

Asked about the reasons why Eesti otsib superstaari was so successful, an interviewee from the production company said:

It is an entertainment competition, and this is the key. It combines elements of a sport competition with good entertainment. And it is the story of someone's dream coming true.

Another interviewee said:

The success behind the show is that audiences are given the opportunity to decide something, to be part of a process by calling for their favourite candidates.

Yet, another interviewee said:

Theory says that it attracts audiences because they can now say that they are part of a global audience. I don't think this is true. I don't think audiences care that this is a global format. The format works well only when it has a very good narrative, when it is compelling and when you can follow the story. And this is the case with this show.

Asked whether he thought it was helpful for the international success of the format that a large company such as FremantleMedia acted as the format's distributor, one interviewee said:

FremantleMedia presents hundreds of formats and not many are as popular as /dols. Also, large distributors, such as FremantleMedia buy the most successful or most promising products for their portfolio anyways. And even though Fremantle was consulting us in producing the show, I would say that their input was not large. 


\section{Main local adaptations options and differences to the original version}

\section{Modification of the name}

In some countries, the word "idol" has a somewhat different connotation compared to what it has in the UK or other Englishspeaking countries. This is also the case in Estonia where the translation of the show's name did not follow the examples of American Idol, Indian Idol, or Australian Idol. Instead, the local production was named Eesti otsib superstaari, which means Estonia is searching for the superstar.

\section{Limited localisation options regarding the logo}

Though the name of the show as part of the logo may change, the logo as such is standard and has to look the same across territories according to the licensing agreement.

\section{Localisation options regarding the jury}

The format features a set of judges, and in most local productions, one of the jury members stands out by making very caustic comments on the contestants' performances. In the UK version, for instance, it is Simon Cowell. While such openly acid comments are not acceptable in all countries, the Estonian production had its "nasty" judge, though he was a milder version of the one in the UK show.

According to the rules of the format, all judges have to be local celebrities known for their activities in the music industry. When the Estonian production company wanted to include a model as a judge, this was not allowed by the format holder. An interviewee at the production company reported:

FremantleMedia needs to approve the judges one selects. And they did not approve the model. Maybe they were right. Even though back then we thought we would choose a model because large parts of the show is how the contestants look.
In some countries, the judges can also select participants during the semi-finals who will then make it to the next round without having to fear negative voting results by the audience. The Estonian production team decided against this option for practical reasons. "It would not have fitted our episode structure," an interviewee at the production company said.

\section{Differences in terms of the scale of the show}

\section{Of course, the show is smaller in Estonia, everything is smaller here. Instead of 20 people in the orchestra, we have five people, for instance. The set is smaller, the number of audience is smaller, also the number of contestants. (Personal interview)}

While the Estonian production attracted about 2,500 people to perform in the auditions of each season, American Idol, for instance, has attracted more than 100,000 participants in one season.

\section{Differences in terms of personalities of the contestants}

One of the key elements of the format is its contestants. In the original version and in most local productions, the contestants are often extroverted and unstable personalities. Such controversial personalities are united in a cast, which often leads to conflicts and scandals that attract audiences.

Due to the small size of the country, local producers in Estonia find it more difficult to create a memorable cast as the sheer number of people who are interested to take part in such a show is, naturally, comparatively small.

What is more, Estonians tend to be more restricted in expressing their emotions in front of others and especially in the presence of a camera than people from many other cultures (Laasi 2010: 44). As a result, Eesti otsib superstaari is less emotional and heated than many other local productions of the format. 
Differences in terms of the stages within one season

The rules for the format include that all local adaptations have to follow a narrative of the above-mentioned stages of the show (auditions, theatre rounds, semi-finals, live shows, grand final). Though this narrative must not deviate from the original, they are some details within each stage that may be adapted for local audiences.

Thus, in the course of the five seasons of the Estonian production, the number of episodes was reduced and so was the number of participants who were allowed into the next rounds. The decisions to do so were made after close consultations between the local production company and the local TV station, and they were made for practical reasons as well as narrative and dramaturgic reasons. As an interviewee at the production company reported:

We changed the number of episodes because we saw that the first stages did not bring in high ratings. I think that the theatre round is the weakest part of the format. In the beginning, we had 100 participants in the theatre round who we had chosen through the auditions, these were too many candidates. Of course, we tried to pick the people on whose stories we would concentrate on, otherwise it would have been too messy for the audience to decide with whom they would like to sympathise. But still, the theatre round is quite a technical round. You have about 100 people and you need to cut the number down to 20. In the US, they have a whole week for what we call the theatre round, they do it in $\mathrm{Hol}-$ lywood, and they call it the Hollywood round. It makes the story bigger. Here, in Estonia we cannot make it so big, so it stays quite technical. Hence, we decided to shorten it.
Differences in terms of the choice of songs performed

Some of the songs performed by the contestants in Eesti otsib superstaari are Estonian songs also sung in Estonian language. Since the market is too small to survive by attracting only the younger audiences, these songs especially serve to attract the older audience groups. As an interviewee at the production company reported:

The songs are in English and Estonian. One of the most difficult things for us was that the participants are allowed to choose their songs themselves, according to the format. The problem is that the young participants all want to only sing in English. But we have to keep a wider audience in mind, so we needed to suggest to them that they sing one or two songs in Estonian. So sometimes, we had the theme that they all had to sing an Estonian song. If they had sung only in English, we would have not reached the audiences above 20. People in their 30s, 40s, and 50 s like Estonian songs.

Asked whether it was not precisely the young audiences that mattered the most in terms of attracting advertising revenues, the interviewee answered:

In Estonia, the first top ten programmes in terms of ratings are published every week. And these ratings look at the whole market. So even if we are the most successful programme with audiences from 15-29 years, we might not appear on this list, and we are not a flagship show. The Estonian market is so small that it is not so good to be only successful with a fragment of the audience. You want to be a flagship show in the country, and these shows are also most interesting to advertisers. 


\section{Critical voices regarding the local production}

Despite the success of Eesti otsib superstaari, interviewees also voiced some criticisms of the programme. For some, the Estonian production suffered from a weak relationship between the licensor and the licensing company as well as the limited resources available in a small market such as Estonia.

Although an interviewee at the production company stated that the workshop notes provided by FremantleMedia were very good and detailed and helped a lot through the process of the production, another interviewee argued that the quality of the local production would have been even better if the relationship between FremantleMedia and the Estonian production company had been closer. Regarding the engagement of the format holders he said:

They certainly don't like it if you destroy their format because then they cannot sell you any of their expertise. But they don't care too much. So they send you the workshop notes, but then everything else is really up to you.

Likewise, an interviewee from the production company said the following:

We sometimes have flying producers who provide a lot of creative input. But with /dols, he was just checking that things were going right, there wasn't much creative input coming from him. He looked at the changes we made, how the format works, at the colours and logos, how many stages and rounds we had, how many people are voted to the next round, etc.

A former Estonian consultant to the programme, however, argued that it was mostly the production company that did not allow for a closer and more productive relationship with the format holder:
They [format licensors in general] sent flying producers. Some of the flying producers I have met were the most amazing and most interesting people I have ever met in my life. They have so much experience. And as a TV producer, it is such a great opportunity to learn when you work with them. They fly out here and they are there for you for five days. You cannot ask Mr. Spielberg to come out here and teach you, but they are the same level people, really. The sad thing here in Estonia, however, is that when they come out here, the local people are hiding. They come to some sort of official meeting, and then that's it. They fear the flying producers like a schoolboy fears a teacher. They think: "I have not prepared so well, so I am a little afraid." There is a missed opportunity, and this is not good for the shows.

Related to this, the interviewee argued that Eesti otsib superstaari did not meet the format's potential, in particular in terms of its emotionality:

The Estonian version of /dols is not really emotional. Everything looks a bit formal. It could have been much more emotional, even here in Estonia. What was missing was not only a better cooperation with the flying producer but also talented writing and talented directing. The problem is financial and that there are not enough talents here.

The lack of human resources was seen as a large problem by this interviewee:

It can happen in a small society such as Estonia that there is nobody who can do such kind of stuff, who is very talented in 
script writing and directing. Or there are not enough people available who can do such things. And if there are only very few people who are good at this, they are expensive.

Not only was there a lack of good script writers and directors in Estonia, according to the interviewee, it was also difficult to find good hosts and jury members:

Casting is crucial, it is very, very crucial. In movie casting you know what types of people you are getting, what to expect from someone. But in reality TV you may experience surprises. And for that it is important that you have the right kind of personalities with the right kind of motivation to be on the show. In small countries, this is difficult to find. In smaller societies, such things sometimes just don't work.

Furthermore, an interviewee pointed out that in small countries usually only very few or only one company specialises in the production of reality TV, which sometimes leads to an overload of work for such companies. For this reason, he said, Ruut quit producing Eesti otsib superstaari when it started to produce a new reality TV programme. Especially the production of reality TV programmes, he said, needed a lot of preparation, for which such companies did not always have the necessary time and capacity:

When producing reality formats, it is all about preparation because you never know when and where exactly things will happen, so you always need to be ready to shoot. You also need to always have a second or third alternative if things don't work out the way you want them to. And they might not work the way you want to because you cannot script. If you script your shows and tell the contestants what to do and say, there will be a lack of emotion, a lack of freshness. You cannot rehearse natural reactions with the contestants.

\section{CONCLUSION}

Based on the example of the Estonian adaptation of /dols, the aim of this article was to study the forces that influence the local production of international formats in terms of differences from the original format version.

In terms of the forces influencing decision-making processes by local producers and network executives as cultural translators (Conway 2011), this article distinguished between two main categories: firstly, forces that have their nature in the cultural differences or cultural similarities between the culture of the format origin and the production culture in the local market (Lacuna and Universal Model; Rohn 2010a, 2011); and secondly forces that have their nature in market and industry logics, including the relationship between the involved companies (Company-Created Universals, Vertical Barrier Chain; Rohn 2010, 2010b).

What becomes obvious in the case of Eesti otsib superstaari, the Estonian production of /dols, is that most changes to the original format were made for practical reasons and not due to cultural considerations or a wish to make the programme more culturally proximate to the local audience. The main reasons behind the differences between the original format version and the Estonian adaptation were due to different cultural grounding of the cast as well as due to the circumstances a small market such as Estonia provides for.

In fact, the most influential force on the production of the local version of /dols in Estonia was the small size of the Estonian TV market. Due to the small market, few financial or human resources are available. Furthermore, the small market offers only space for a very limited number of production companies focusing on reality TV, 
as a result of which not many shows can be produced at the same time. Similarly, a small TV market does not allow for a large fragmentation of the audience market as an audience fragment may not be large enough to make use of economies of scale. Hence, programmes need to attract a wider audience than just the young audiences, which are usually the main target group for an /dols adaptation.

Regarding the Vertical Barrier Chain, political reasons did not influence the decision-making in the adaptation process, though legal reasons in the form of the licensing agreement did. Most of the production decisions, however, had their roots in the economics of the market. In terms of the Lacuna and Universal Model, the programming elements for which the show was successful in Estonia as it was elsewhere (Content Universals) included that it was a mixture of competition and entertainment as well as a story about someone's dream come true. Furthermore, the show allows audiences to be part of the show through their voting (Audience-Created Universals). Less important was the production assistance of the licensor through the flying producers (Company-Created Universals). In terms of programming elements that differed from the original version due to cultural differences (Lacunae), the name of the Estonian show was not only in Estonian language (Capital Lacuna), the word "idol" was changed into "superstar" and Estonian songs were introduced (Content Lacuna). Furthermore, the style of the show was slightly different due to the different cultural grounding of the cast (Production Lacuna).

In terms of the relationship between the format holder, the local production company, and the local TV station, an interviewee stated that the flying producer from the format holder could have provided more creative input, if the local production company had been ready for it and had overcome its fear of a teacher-student kind of relationship. When the local producer intended to incorporate a model as a jury member, this was the only occasion where the rules set by the format owner stopped the plans of the producer. The intended introduction of a model to the jury was the only occasion where the licensor intervened and stopped the plans. Most of the changes from the original version were for practical reasons, such as the decrease in the number of episodes and number of contestants who made it to the next level, and they were discussed in a close relationship between the local production company and the local TV station.

This article emphasised the role that market and industry logics play in the translation process of international TV formats in local markets. What is available in the global TV market depends very much on the economics in the markets, and not necessarily on the original format and its cultural shareability. The most decisive force that influences what is available to audiences in Estonia appears to be the small size of the Estonian TV market that leads to specific market and industry logics. 


\section{REFERENCES}

Aalto, Pami 2003. Constructing Post-Soviet Geopolitics in Estonia. London: Frank Cass.

Aslama, Minna; Pantti, Mervi M. 2007. ‘Flag-ging Finnishness: Reproducing National Identity in Reality Television'. - Television and New Media, 8, 1, 49-67. Beeden, Alexandra; DeBruin, Joost 2010. 'The Office: Articulations of National Identity in Television Format Adaptation'. - Television and New Media, 11, 3, 3-19. Conway, Kyle 2011. 'Cultural Translation, Global Television Studies, and the Circulation of Telenovelas in the United States.' - International Journal of Cultural Studies, 15, 6, 583-598.

DeBruin, Joost 2012. 'NZ Idol: Nation Building Through Format Adaptation': - Tasha Oren, Sharon Shahaf (eds.), Global Television Formats: Understanding Television across Borders. New York, London: Routledge, 223-241. Eco, Umberto 1979. The Role of the Reader: Explorations in the Semiotics of Texts. Bloomington: Indiana University Press.

Eesti Rahvusringhääling 2009. Majandusaasta aruanne 2009. http://err.ee/files/ERR_majandusaasta_ aruanne_2009.pdf (23 January 2014).

Eesti Statistikaamet 2011. Minifacts about Estonia 2011. http://www.stat.ee/publication-download-pdf? publication_id=25643 (23 January 2014).

Fiske, John 1987. Television Culture. London, New York: Routledge.

Fremantle Media 2014. Idols.

http://www.fremantlemedia.com/Production/Our_ Brands/Idols.aspx (23 January 2014).

Hofstede, Geert 2001. Culture's Consequences: Comparing Values, Behaviors, Institutions, and Organizations across Nations. Thousand Oaks: Sage.

Hoskins, Colin; Mirus, Rolf 1988. 'Reasons for the US Dominance of the International Trade in Television Programmes'. - Media, Culture \& Society, 10, 4, 499515.

Hoskins, Colin; McFadyen, Stuart; Finn, Adam 1994. 'The Environment in which Cultural Industries Operate and Some Implications. - Canadian Journal of Communication, 19, 3. http://www.cjc-online.ca/index.php/ journal/article/view/824/730 (6 November 2014). Huff, Richard M. 2006. Reality Television. Westport: Praeger.

Iwabuchi, Koichi 2002. Recentering Globalization: Popular Culture and Japanese Transnationalism. Durham: Duke University Press.

Kalmus, Veronika; Masso, Anu; Lauristin, Marju 2013. 'Preferences in Media Use and Perception of Intergenerational Differences among Age Groups in Estonia: A Cultural Approach to Media Generations. - Northern Lights, 11, 15-34.

Kretschmer, Martin; Singh, Sukhpreet 2010. Exploiting 'Idols': A Case Study of International TV Formats Trading in the Absence of Intellectual Property Protection. http://tvformats.bournemouth.ac.uk/Downloads/ Exploiting_Idols.pdf (6 November 2014).

Laasi, Laura 2010. Reality Television: Adapting International Formats in Estonia. Master's thesis. Tallinn: Tallinn University Baltic Film and Media School.

Lowe, Gregory Ferrell; Berg, Christian Edelvold; Nissen, Christian S. 2011. 'Size Matters for TV Broadcasting Policy.' - Gregory Ferrell Lowe, Christian S. Nissen (eds.), Small Among Giants: Television Broadcasting in Smaller Countries. Göteborg: Nordicom, 21-42.

Mavise 2012. Database of TV Companies and TV Channels in the European Union and Candidate Countries. http://mavise.obs.coe.int/ (23 January 2014). Moran, Albert Joseph 2004. 'The Pie and the Crust: Television Program Formats.' - Robert C. Allen, Annette Hill (eds.), The Television Studies Reader. London: Routledge, 258-266.

Olson, Scott Robert 1999. Hollywood Planet: Global Media and the Competitive Advantage of Narrative Transparency. Mahwah: Lawrence Erlbaum Associates.
Open Society Institute 2005. Television across Europe: Regulation, Policy and Independence. Volume 1. Budapest, New York: Open Society Institute. http://www.opensocietyfoundations.org/sites/default/ files/volone_20051011_0.pdf (14 November 2014). Örnebring, Henrik 2011. Estonia: A Country Report for the ECR-funded Project on Media and Democracy in Central and Eastern Europe. http://mde.politics.ox.ac. uk/ (23 January 2014).

Puppis, Manuel; d'Haenens, Leen; Steinmaurer, Thomas; Künzler, Matthias 2009. 'The European and Global Dimension: Taking Small Media Systems Research to the Next Level.' - The International Communication Gazette, 71, 1-2, 105-112.

Rohn, Ulrike 2010a. Cultural Barriers to the Success of Foreign Media Content - Western Media in China, India, and Japan. Frankfurt am Main: Peter Lang.

Rohn, Ulrike 2010b. 'The Vertical Barrier Chain:

A New Interdisciplinary Framework for Understanding International Media Strategies'. Paper presented at the 9th World Media Economics and Management Conference, Bogotá, Colombia, 2-6 June 2010.

Rohn, Ulrike 2011. 'Lacuna or Universal? Introducing a New Model for Understanding Cross-cultural audience demand: - Media, Culture \& Society, 33, 4, 631-641.

Root, Franklin R. 1994. Entry Strategies for International Markets. New York: Lexington Books.

Siegert, Gabriele 2006. 'The Role of Small Countries in Media Competition in Europe'. - Jürgen Heinrich, Gerd

G. Kopper (eds.), Media Economics in Europe. Berlin: Vistas, 191-210.

Singhal, Arvind; Udornpim, Kant 1997. ‘Cultural Shareability, Archetypes and Television Soaps: 'Oshindrome' in Thailand'. - Gazette, 59, 3, 171-188.

Stetka, Vaclav 2012. 'From Global to (G)local: Changing Patterns of Television Program Flows and Audience Preferences in Central and Eastern Europe.. Journal of Popular Film and Television, 40, 3, 109-118. Straubhaar, Joseph 1991. 'Beyond Media Imperialism: Asymmetrical Interdependence and Cultural Proximity'. - Critical Studies in Media Communication, 8, 1-11.

TNS Emor 2009. Teleauditooriumi ülevaade detsembrikuus 2009. http://www.emor.ee/teleauditooriumiulevaade-detsembrikuus-2009 (23 January 2014). TNS Emor 2014. Teleauditooriumi ülevaade detsembrikuus 2013. http://www.emor.ee/teleauditooriumiulevaade-detsembrikuus-2013 (23 January 2014). Trappel, Josef 2011. 'Structure and Dynamics: The Television Broadcasting Industry in Smaller Countries' - Gregory Ferrell Lowe, Christian S. Nissen (eds.),

Small among Giants: Television Broadcasting in Smaller Countries. Göteborg: Nordicom, 111-131.

Turner, Graeme 2005. 'Cultural Identity, Soap Narrative, and Reality TV'. - Television and New Media, 6, 4, 415-22.

Vihalemm, Peeter 2006. 'Media Use in Estonia: Trends and Patterns'. - Nordicom Review, 27, 1, 17-29. Vihalemm, Peeter; Lauristin, Marju; Kõuts, Ragne 2012. 'Trends in Estonian Media Landscape in 2000-2001'. Media Transformations, 6, 12-63. 